\title{
Life Cycle Carbon Emission Analyzing of Rural Residential Energy Efficiency Retrofit-A Case Study of Gansu province
}

\author{
Qiangnian $\mathrm{Li}^{1}$, Tongze Han ${ }^{1, *}$, Changlin $\mathrm{Niu}^{1,2}$ and Ping Liu ${ }^{1}$ \\ ${ }^{1}$ School of Civil Engineering, Lanzhou University of Technology, Lanzhou, China \\ ${ }^{2}$ GCIGC Technology Development CO., LTD., Lanzhou, China
}

\begin{abstract}
Objective To study and analyze the life-cycle carbon emissions of existing rural residential energy retrofit projects to provide theoretical and data support for local rural green development and sustainable construction. Methods Life cycle analysis (LCA) was used to analyze and compare the life cycle carbon emissions (LCE) of a rural residential envelope energy efficiency retrofitting project in central Gansu. Results It was found that rural dwellings have a very high potential for energy efficiency retrofitting, and the contribution of retrofitted homes to $\mathrm{CO}_{2}$ emissions reduction can reach more than $30 \%$ over the whole life cycle. Secondly, during the retrofitting process, neglected in previous studies, carbon emissions account for about a quarter of the LCE. It is concluded that introducing LCA into evaluating rural residential energy retrofit projects' energy-saving and emission reduction benefits is more scientific, reasonable, and necessary.
\end{abstract}

\section{Introduction}

Due to a large amount of greenhouse gas emissions, global climate system warming accelerated in just past 2019, and many historical records such as early weathering period, glacier melting, and sea-level rise were set, and climate extremes increased significantly. In response to the global warming trend, China proposed at the United Nations General Assembly in September 2020 that "carbon dioxide emissions should strive to peak by 2030 and work towards carbon neutrality by 2060" [1]. China's construction industry currently accounts for about $40 \%$ of total energy consumption and $20 \%$ of greenhouse gas emissions [2]. Some statistics show that the total floor area of existing residential buildings in rural areas of China is about 24 billion square meters, most of which do not adopt energy-efficient technologies and have backward and inefficient heating methods, leading to a yearly increase in energy consumption in rural residential buildings, resulting in a large amount of unnecessary $\mathrm{CO} 2$ and other harmful gas emissions [3, 4]. In response to the above problems, the Ministry of Housing and UrbanRural Development and the Ministry of Industry and Information Technology attached great importance to this issue and issued the Notice on the Construction of Green Rural Houses. Thus, it can be seen that a large number of existing dwellings in rural areas of China have great potential for energy-saving renovation. In addition, the energy-saving retrofit and life cycle emissions (LCE) analysis of such houses is of great significance for China to achieve the goal of "double carbon."

Many scholars have studied the whole life cycle carbon emissions of buildings. Xie Baichen et al. introduced the emissions of $\mathrm{CH}_{4}$ and $\mathrm{N}_{2} \mathrm{O}$ based on LCE and evaluated a research building [5]; Cai Weiguang used the Monte Carlo model to simulate the uncertainties in the life cycle of a building, to measure the LCE of a building more accurately [6]; Qin Ardian et al. who also studied the LCE of subway stations from a life-cycle perspective [7].

For the study of carbon emission of rural houses, both domestic and international have focused on calculating and evaluating energy consumption and carbon emission in its operation phase, especially in the winter heating phase. For example, Guo Jianhong et al. conducted a comparative analysis of the operational energy consumption and carbon emissions of existing rural dwellings in Hebei Province after different retrofitting schemes [8]; J Y Dong et al. used a BIM platform to simulate and compare the energy consumption of rural dwellings in cold regions before and after retrofitting [9]; $\mathrm{Xu}$ Juan used a questionnaire method to systematically investigate and calculate the housing energy consumption of 660 rural households in 11 provinces in northern China over two years [10]. Xu Juan conducted a systematic study and calculation of the energy consumption of 660 rural households in 11 provinces in northern China using a questionnaire method over two years [10].

According to the current status of related studies, it can be found that there are few LCE studies for energy efficiency retrofitting of existing rural houses. Since rural homes have a large inventory from a macroscopic point of view and generate a large amount of energy consumption at all life cycle stages, carbon emission measurement only from the operation stage is not comprehensive enough. This study is expected to provide theoretical and data support for local rural green development and sustainable construction.

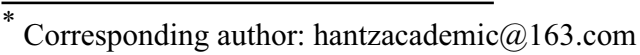




\section{Methodology}

With the increasing awareness of environmental protection and the better understanding of the impacts that may accompany the production and consumption of products, there is a desire to establish methods to better understand and account for these impacts. Life cycle assessment (LCA) is one of the techniques developed with this purpose in mind [11]. Life cycle refers to the entire process of a product (or service) from the acquisition of raw materials, production, use until disposal, i.e., from the cradle to the grave. As defined by ISO 14040, life cycle assessment is a method used to assess the environmental factors and potential impacts associated with a product (or service) by compiling inventory records of the relevant inputs and outputs of a system, evaluate the potential environmental impacts associated with these inputs and outputs, and interpreting the results of the analysis of inventory records and ecological impacts according to the objectives of the life cycle assessment study.

\subsection{Determination of the calculation boundary}

At present, most of the existing building carbon accounting models divide the life cycle of buildings into the physical phase and the operational phase. The physical step includes carbon emissions from the production and transportation of building materials, construction, maintenance, and demolition of buildings. The active phase includes carbon emissions from heating, air conditioning systems, ventilation, lighting, electrical equipment, domestic hot water, and other service facilities [12].

However, rural existing residential energy retrofit projects are different from a new build. The energy retrofit projects for existing buildings need to be adjusted according to the existing carbon emission measurement model to redefine the time boundary of the project, as shown in Figure 1 [12].

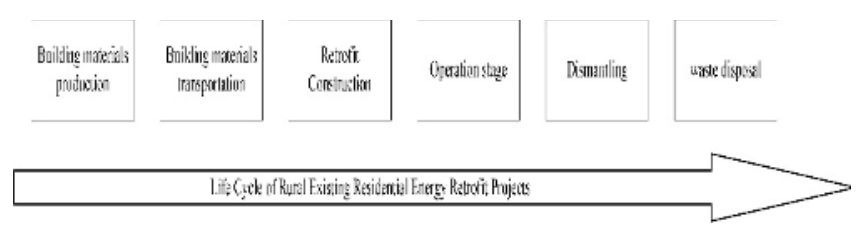

Fig.1. The life cycle of rural existing residential energy retrofit projects

\subsection{Carbon emission calculation model}

This paper establishes a carbon emission calculation model for existing rural residential energy retrofit projects based on the calculation boundary identified above and other literature. The values of the carbon emission factors are referred to the "Standard for Calculation of Building Carbon Emissions" GB/T51366-2019 [13] and the calculation model established by Qian Prim et al. in 2018 for the whole life cycle carbon emissions of energy efficiency retrofitting of existing buildings in Shenzhen [14].

\subsubsection{Building materials production stage}

According to the bill of quantities of the renovation project for the types and amounts of building materials required, the carbon emissions generated in the process are calculated according to the "Standard for Calculation of Carbon Emissions from Buildings" GB/T51366-2019, with the following formula. $C_{\mathrm{JC}}=\frac{C_{\mathrm{sc}}+C_{\mathrm{ys}}}{A}(1)$. Where: CJC is the carbon emission per unit building area in the production and transportation stage of building materials $\left(\mathrm{kgCO}_{2} \mathrm{e} / \mathrm{m}^{2}\right)$; $\mathrm{Csc}$ is the carbon emission in the production stage of building materials $\left(\mathrm{kgCO}_{2} \mathrm{e}\right)$; Cys is the carbon emission in the transportation process of building materials $\left(\mathrm{kgCO}_{2} \mathrm{e}\right)$; $\mathrm{A}$ is the building area $\left(\mathrm{m}^{2}\right)$. The calculation of the production stage of building materials mainly considers the type of building materials required, the consumption of building materials, and the carbon emission factor of producing such materials. The specific calculation formula is as follows: $C_{S C}=\sum_{i=1}^{n} M_{i} F_{i}(2)$ Where: Csc is the carbon emission of the production stage of building materials $\left(\mathrm{kgCO}_{2}\right)$; $\mathrm{Mi}$ is the consumption of the ith means building material; Fi is the carbon emission factor of the ith means building material ( $\mathrm{kgCO}_{2} /$ unit quantity of building materials).

\subsubsection{Building materials transportation stage}

The primary considerations of the building materials transportation stage are the consumption of building materials required for the renovation project, the transportation distance, and the carbon emission factor of the transportation method. The specific calculation formula is as follows: $C_{\mathrm{ys}}=\sum_{i=1}^{n} M_{i} D_{i} T_{i}$ (3) Where: Cys is the carbon emission of the transportation process of building materials $\left(\mathrm{kgCO}_{2}\right)$; $\mathrm{Mi}$ is the consumption of the ith means building material $(\mathrm{t})$; $\mathrm{Di}$ is the average transportation distance of the ith building material $(\mathrm{km})$; $\mathrm{Ti}$ is the carbon emission factor of the transportation distance per unit weight under the transportation mode of the ith building material $\left[\mathrm{kgCO}_{2} /(\mathrm{t}-\mathrm{km})\right]$.

\subsubsection{Renovation construction stage}

The carbon emission accounting in the renovation of existing residential energy-saving projects should include the carbon emissions generated by each sub-project and each construction measure. The calculation time should be calculated from the beginning of construction to the end of completion. The carbon emissions from various types of machinery, small temporary equipment, on-site mixing of concrete, mortar, paint, and other materials during construction should be included in the total emissions of the renovation construction phase. Specific calculation public as follows. $C_{\mathrm{JZ}}=\sum_{i=1}^{n} E_{\mathrm{j}_{i}} E F_{i}$ (4). Where: CJZ is the carbon emission of the building construction stage $\left(\mathrm{kgCO}_{2}\right)$; Ejz, $\mathrm{i}$ is the total amount of 
the ith type of energy used in the building construction stage ( $\mathrm{kWh}$ or $\mathrm{kg})$; EFi is the carbon emission factor of the ith type of energy $\left(\mathrm{kgCO}_{2} / \mathrm{kWh}\right.$ or $\left.\mathrm{kgCO}_{2} / \mathrm{kg}\right)$.

\subsubsection{Operation stage}

The primary sources of carbon emissions in the use phase of the energy-efficient renovated rural houses are related to summer cooling, winter heating, domestic water, and electricity consumption. According to the Energy Conservation Design Standard for Rural Residential Buildings GBT 50824-2013 [15] and the Notice on the Construction of Green Agricultural Houses issued by the Ministry of Housing and Construction, this study defines the carbon emission calculation period of the operation phase as 30 years. The specific calculation formula is as follows. $C_{\mathrm{M}}=\left[\sum_{i=1}^{n}\left(E_{i} E F_{i}\right)-C_{\mathrm{p}}\right] y(5)$. Where: $\mathrm{CM}$ is the carbon emission in the operation phase of the building $\left(\mathrm{kgCO}_{2}\right)$; Ei is the annual consumption of the $\mathrm{i}$-th type of energy of the building (unit/a); EFi is the carbon emission factor of the $i$-th type of energy, $i$ is the type of terminal energy consumed by the building, including electricity, gas, oil, municipal heat, etc.; $\mathrm{j}$ is the type of energy system of the building, including heating and air conditioning, lighting, domestic hot water system, etc.; $\mathrm{Cp}$ is the carbon sink of the green space of the building system annual carbon reduction $\left(\mathrm{kgCO}_{2} / \mathrm{a}\right)$; and $\mathrm{y}$ is the building design life (a). In this study, all types of energy consumption in the post-retrofit use phase were simulated using eQUEST 3.65 software.

\subsubsection{Dismantling stage}

Since there are few studies on carbon emission measurement for the demolition stage, this study draws on the existing literature to argue that the main factors that should be considered to measure the carbon emission of the demolition stage of a building are its engineering volume, the process and the carbon emission factor of the process [12]. The specific calculation formula is as follows. $C_{c c}=\sum_{i=1}^{n} C_{i F i}$ (6). Where: $\mathrm{Ccc}$ is the carbon emission of the building demolition stage $\left(\mathrm{kgCO}_{2}\right)$; $\mathrm{Ci}$ is the engineering volume of the i-th demolition process; Fi is the carbon emission factor of the i-th process.

\subsubsection{Waste disposal stage}

The sources of carbon emissions in the post-demolition waste disposal phase are mainly in the transportation and landfill of waste. If there are building materials that can be recycled, they can moderately offset some of the carbon emissions generated during the production of building materials. The specific calculation formula is as follows [11]. $C_{\mathrm{w}}=C_{\mathrm{t}}+C_{\mathrm{d}}+C_{\mathrm{g}}(7) \cdot C_{\mathrm{t}}=\sum_{i=1}^{n} m_{i} l_{i} k_{\mathrm{t} j}$ (8). $C_{\mathrm{d}}=\sum_{i=1}^{n} D m_{i}(1-R)$ (9). $C_{\mathrm{g}}=\sum_{i=1}^{n} m_{i} R k_{\mathrm{mi}} R_{i}$ (10). Where: $\mathrm{CW}$ is the carbon emission of the waste treatment process $\left(\mathrm{kgCO}_{2}\right)$; li is the transportation distance of waste $(\mathrm{km})$; D is the carbon emission factor per unit of construction waste landfill $\left(\mathrm{kgCO}_{2}\right)$; $\mathrm{Ri}$ is the recycling rate $(\%)$; $\mathrm{R}$ is the ratio of construction waste recycling to save carbon emission of building materials production (\%). Among them, the recycling rate of steel, aluminum, and other metal materials is $100 \%$, the recycling rate of waste such as thermal insulation wool, asphalt waterproofing membrane, and polystyrene sheet is 0 , and the remaining part of the list is all landfilled.

\section{Case Study}

\subsection{Project Introduction}

The rural residence is located in Yongdeng County, Lanzhou City, Gansu Province, with a residential base area of $200 \mathrm{~m}^{2}$, a land area of $112.7 \mathrm{~m}^{2}$, a building area of $221.8 \mathrm{~m}^{2}$, usable space of $185.2 \mathrm{~m}^{2}$, a functional area coefficient of 0.835 , a building density of $56.4 \%$, and a floor area ratio of 1.1. The resident population is four people. The structure was modified according to the specific needs, living habits, and winter resident population of the occupants [16-18], the Energy Conservation Design Standard for Rural Residential Buildings GBT-50824-2013 [15], the Green Retrofit Assessment Standard for Existing Buildings JGJ26-2018 [19] and the Technical Specification for External Wall Internal Insulation IGJT261-2011 [20]. A retrofitting scheme was proposed for the building envelope, and a BIM model was established (Fig 2). Furthermore, the specific practices of the envelope are shown in Table 1.

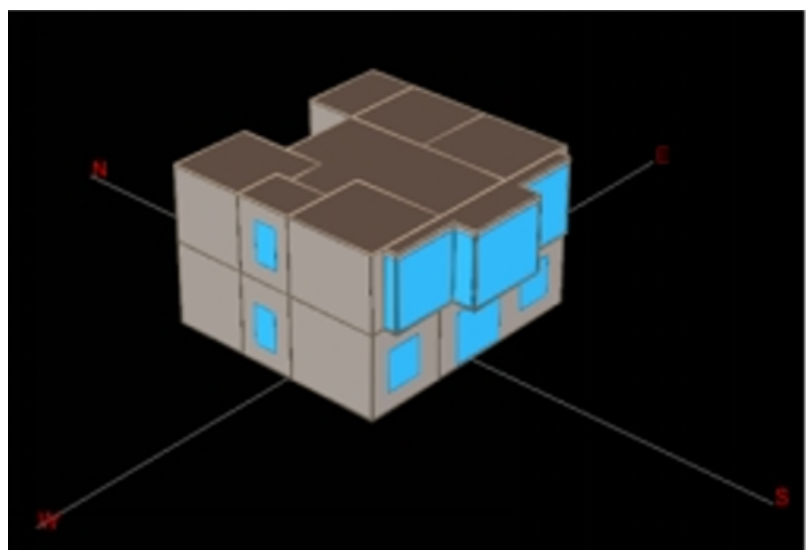

Fig.2. Retrofit Case Model 
Table 1 Specific approach to energy efficiency retrofits

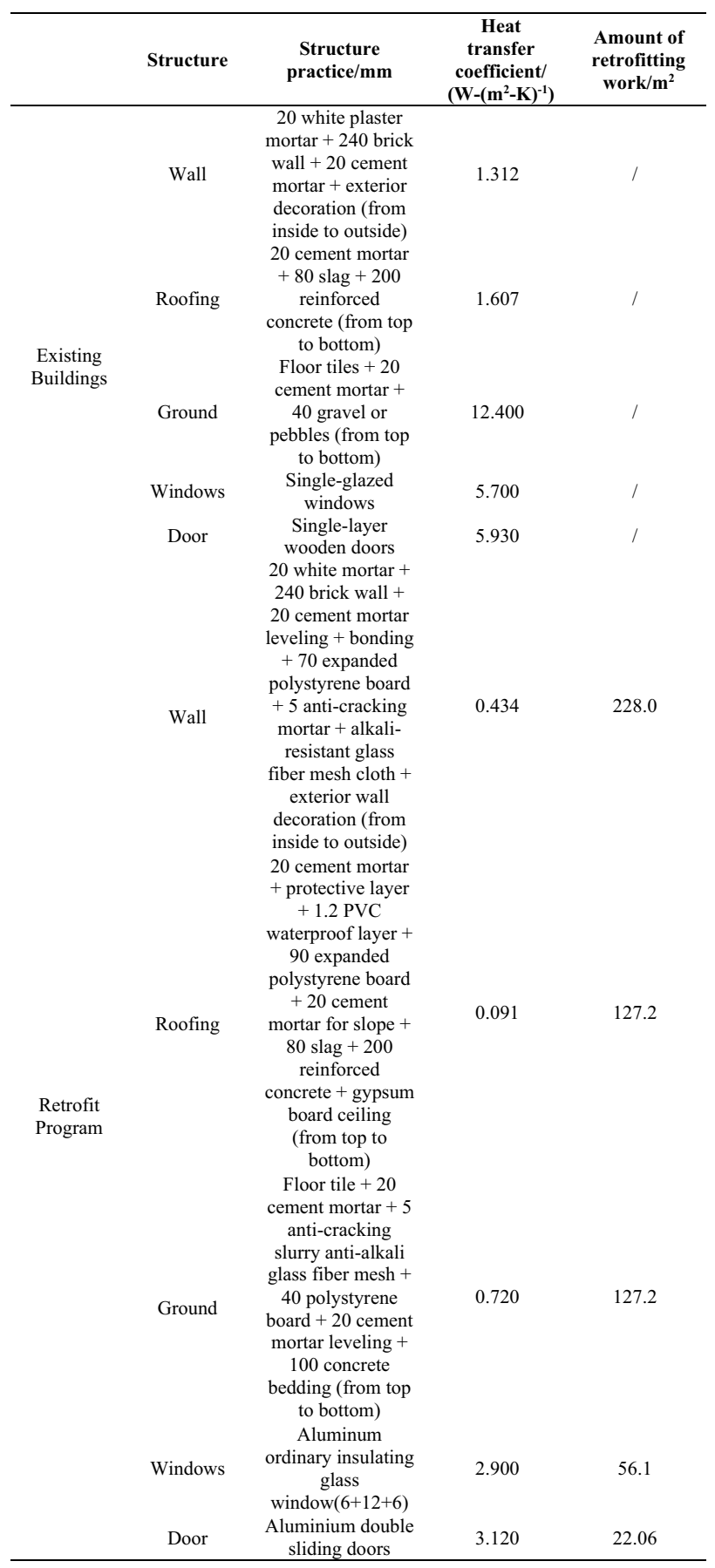

\subsection{Life cycle carbon emissions accounting}

Based on the above research methodology, this study uses the corresponding accounts provided by the householder and Table 1 to prepare a bill of quantities to calculate and compare the life-cycle carbon emissions of the existing house with those of the retrofitted house, to analyze the carbon benefits of the retrofit project. eQUEST software was used to simulate the energy consumption during its use phase, with the indoor temperature set at $26^{\circ} \mathrm{C}$ in summer and $18^{\circ} \mathrm{C}$ in winter (heating from October 15 to
March 15), $5 \mathrm{~W} / \mathrm{m}^{2}$ for lights, $10 \mathrm{~W} / \mathrm{m}^{2}$ for equipment, and four people. The specific results are shown in Table 2 .

Table 2Calculation results of life cycle carbon emissions

\begin{tabular}{ccc}
\hline Stage & Exciting & Retrofitting \\
\hline $\begin{array}{c}\text { Building materials production } \\
(\mathrm{kgCO})\end{array}$ & $/$ & 46611.07 \\
Building materials transportation & $/$ & 6397.1 \\
$\left(\mathrm{kgCO}_{2}\right)$ & & \\
Retrofit construction $\left(\mathrm{kgCO}_{2}\right)$ & $/$ & 1993.8 \\
Operation stage $\left(\mathrm{kgCO}_{2}\right)$ & 333128.1 & 174458.3 \\
Dismantling $\left(\mathrm{kgCO}_{2}\right)$ & 558.9 & 558.9 \\
Waste disposal $\left(\mathrm{kgCO}_{2}\right)$ & 3320.4 & -1553.4 \\
Aggregate $\left(\mathrm{tCO}_{2}\right)$ & 337.1 & 228.5 \\
\hline
\end{tabular}

\subsection{Life cycle carbon emission analyzing}

\subsubsection{Carbon Emission Analysis in the Retrofit Phase}

The retrofit phase in this study includes the production of building materials for the retrofit project, the transportation of building materials, and the construction of the retrofit. As shown in Figure3, the energy efficiency retrofit project produced a total of 55 tons of $\mathrm{CO} 2$ during this phase, with the production and transportation of building materials accounting for about a quarter of the total life-cycle emissions of 53 tons. As shown in Figure 4 , the three building materials with the highest carbon emissions during the production phase are aluminum doors and windows (19.87 tons), silicate cement (11.20 tons), and polystyrene insulation board (7.43 tons). The rest of the primary carbon emissions of building materials production stage is minor, such as PVC waterproofing membrane is about 5.84 tons, lime is about 1.43 tons, while carbon emissions are generated by sand, stone, water, etc. are negligible. According to the default transportation distance of building materials in the "Construction Carbon Emission Calculation Standard," the carbon emission at this stage accounts for 3\% of the total, and the carbon emission is relatively small, accounting for $1 \%$ of the whole because the construction of rural residential renovation is mostly self-built and dominated by manual work. It can be seen that the carbon emissions in the stage of the energy-saving renovation project have a non-negligible contribution to the whole life cycle carbon emissions, and it is more scientific and reasonable to use the entire life cycle analysis method rather than just the use stage after the renovation to evaluate the carbon emission benefits of the energysaving renovation of existing buildings. 


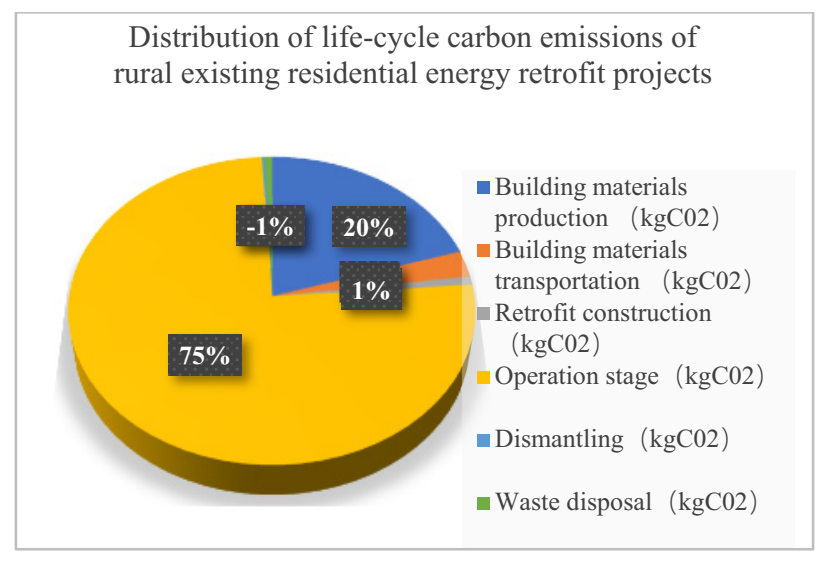

Fig.3.Distribution of life-cycle carbon emissions of rural existing residential energy retrofit projects

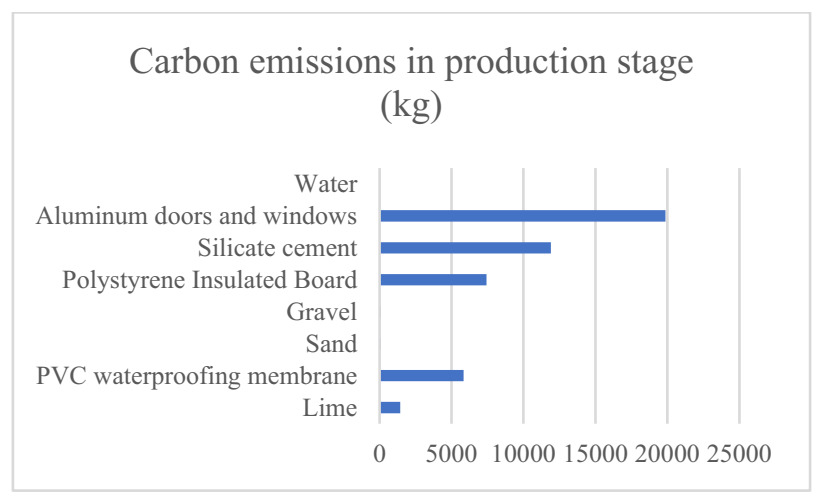

Fig.4.Carbon emissions by building materials production stage

\subsubsection{Carbon emission analysis of the use phase after retrofitting}

In the 30-year life cycle, the carbon emissions from the use phase of the retrofitted house account for about $75 \%$ of the total life-cycle carbon emissions, with the preprimary carbon emissions coming from energy consumption for winter heating and electricity for daily use. According to the simulation results of eQUEST software, the carbon emission in the use phase of the renovated house is reduced from $50.25 \mathrm{kgCO}_{2} \cdot \mathrm{m}^{2} \cdot \mathrm{a}^{-1}$ before the renovation to $26.22 \mathrm{kgCO} \cdot \mathrm{m}^{2} \cdot \mathrm{a}^{-1}$ per unit $\operatorname{ar} 47.82 \%$, which proves that the energy-saving renovation has a significant emission reduction effect. However, the reality is that domestic energy consumption in the area is mainly fuelwood, straw, non-renewable and inefficient [21].one of the main factors contributing to the unsatisfactory carbon emission benefits of the energy efficiency retrofit.

\subsubsection{Analysis of carbon emissions in the closing phase}

The end-stage is the demolition and waste disposal stage of the project. As shown in Figure 3, the carbon emissions from the demolition and waste disposal phases account for a tiny portion of the total life-cycle emissions, about $1 \%$. It is noteworthy that the carbon emissions from the waste disposal phase of the retrofitted rural houses are harmful due to the use of bridged aluminum windows and doors, which have a high recycling value and can offset some of the carbon emissions from the production of the building materials. This phenomenon also proves that using environmentally friendly recyclable building materials can contribute to energy saving and emission reduction goals in the building industry.

In summary, although the retrofitting project generated an additional 55 tons of carbon emissions during the retrofitting process, the energy efficiency of the original dwelling was significantly improved during the use phase after retrofitting, and the emission reduction contribution per unit area was as high as more than $47 \%$. As a whole, the total $\mathrm{CO}_{2}$ emission of existing rural houses is about 337.1 tons in the whole life cycle, while the total $\mathrm{CO}_{2}$ emission of the places after energy-saving renovation is about 228.5 tons. The carbon emission reduction benefit reaches $32.2 \%$, which proves that rural houses have a high potential for energy saving and emission reduction and the need for energy-saving renovation.

\section{Conclusion}

With the increasing concern about environmental problems, China, as the world's largest developing country, has put the goal of achieving "peak carbon and carbon neutrality" on its agenda. This study analyzed the life-cycle carbon emissions of a rural housing retrofit project in Gansu Province using a life-cycle analysis method. The following conclusions were drawn to reference the early achievement of the "double carbon" goal and the construction of an ecologically livable countryside.

(1) Through calculation, it is found that the retrofitting of existing residential buildings also generates a large number of carbon emissions in the pre-use retrofitting phase accounting for about $1 / 4$ of the whole life cycle emissions, and this part of carbon emissions is often neglected in previous studies. Therefore, it is more scientific and reasonable to apply the entire life cycle analysis method to evaluating energy-saving and emission reduction benefits of existing buildings' energy-saving renovation.

(2) Existing rural dwellings have great potential for energy saving and emission reduction retrofitting. By analyzing the carbon emissions of the cases, it can be seen from the analysis that the energy-efficient retrofitted dwellings can reduce $\mathrm{CO}_{2}$ emissions by more than $30 \%$. The use phase of carbon emissions accounts for about $75 \%$ of the LCE, most caused by inefficient fossil fuels. It will make a significant contribution to achieving the "double carbon" goal.

(3) From the results of this study, it can be seen that the recycling of waste can offset part of the carbon emissions in the waste disposal stage after building demolition. However, in reality, the disposal methods for building debris are still mainly landfill-based. Strategies to improve waste recycling rate include secondary use of waste concrete to make aggregates [22]. It can also effectively reduce the LCE of buildings. 
This study analyzes the LCE of a rural residential energy efficiency retrofit project in Gansu from a microscopic perspective. Other methods can be used in the future to analyze existing rural buildings in different regions at a macroscopic level. Other GHG emission analyses should also be introduced [5], providing a more informative data basis for local governments when formulating emission reduction planning policies.

\section{Acknowledgments:}

This work was financially supported by the National Natural Science Foundation of China (72061023) and the Natural Science Foundation of Gansu Province (20JR10RA173) fund.

\section{References}

1. Xi Jinping, speech at the general debate of the 75th session of the UN General Assembly [R]. Beijing, September 30, 2020

2. China Building Energy Conservation Association Energy Consumption Special Committee, China Building Energy Consumption Research Report (2020) [R].2021.

3. Zheng, G., and W. Bu. "Review of Heating Methods for Rural Houses in China." Energies 11.12(2018).

4. He, B. J., et al. "Overview of rural building energy efficiency in China." Energy Policy 69. Jun. (2014):385-396.

5. Xie, B. C., et al. "Assessment of energy and emission performance of a green scientific research building in Beijing, China." Energy and Buildings 224(2020):110248.

6. Ma, M., et al. "Low carbon roadmap of the residential building sector in China: Historical mitigation and prospective peak." Applied Energy 273 (2020): 115247.

7. Qin Ardian, Yuan Yanping, Jiang Fujian. " A study on the whole life cycle carbon emission of subway station buildings: an example of a station on Line 3 in Chengdu. " Construction Economics, 2020(S1).

8. Guo Jianhong, Zhang Shun, Ma Kunru. "Analysis of the benefits of on-demand energy-saving renovation of existing buildings in rural areas in cold northern regions: an example of a farmhouse in Fuping County, Baoding City, Hebei Province. " Hebei Industrial Science and Technology, 37(5):8.

9. Dong, J. Y., et al. "Thermal environment analysis and energy conservation research of rural residence in cold regions of China based on BIM platform." IOP Conference Series Earth and Environmental science 69.1(2017):012009.

10. Xu, J., W. Gao, and Huoxiaoping. "Analysis on energy consumption of rural building based on a survey in northern China." Energy for Sustainable Development 47.DEC.(2018):34-38.
11. "Environmental Management Life Cycle Assessment Principles and Framework." GB/T 24040-2008

12. Chen Sha, Cui Dongge, Zhang Huijuan. "Carbon emission calculation method and case study of buildings. "Journal of Beijing University of Technology, v.42.04(2016):120-126.

13. The standard for Calculating Carbon Emissions from Buildings.GB/T 51366-2019

14. Qian Snap, Feng Tao, Ma Yaoyao, et al. "Carbon emission calculation method for retrofitting existing public buildings in Shenzhen." Construction Technology, 47.S3(2018):98-101.

15. Energy Conservation Design Standards for Rural Residential Buildings.GBT 50824-2013

16. Ma, L., et al. "Farmers' Rural-To-Urban Migration, Influencing Factors and Development Framework: A Case Study of Sihe Village of Gansu, China." International Journal of Environmental Research and Public Health 16.5(2019).

17. Chen, N. C., et al. "Environmental Satisfaction, Residential Satisfaction, and Place Attachment: The Cases of Long-Term Residents in Rural and Urban Areas in China." Sustainability 11(2019).

18. Liu, Y., et al. "Field study of different thermal requirements based on the indoor activities patterns of rural residents in winter in Northwest China." Science and Technology for the Built Environment (2018):0-0.

19. Evaluation Standards for Green Retrofitting of Existing Buildings.JGJ26-2018.

20. Technical Specification for Thermal Insulation in External Walls.IGJT261-2011.

21. Wang, R., and Z. Jiang. "Energy consumption in China's rural areas: A study based on the village energy survey." Journal of Cleaner Production 143.FEB.1(2017):452-461.

22. Yang M. B., Su Y., Li Z. J., Chen C. P., Chen B. X., Guo W. E., Wang H. C. "Pilot process research on the production of fully recycled fine aggregate from waste concrete. "Concrete No.372.10(2020):85-89. 